\title{
Humanización
}

\section{Ética dos cuidados como base para a implementação de uma política pública brasileira de humanização}

Ethics of Care as a Base for the Implementation of a Brazilian Public Policy of Humanization

(2) Autor

\author{
Sabrina Pontes Buziquia \\ Pontifícia Universidade Católica do Paraná \\ E-mail: sabrina.buziquia@gmail.com \\ Yasmin Elero \\ Pontifícia Universidade Católica do Paraná \\ E-mail: yasminelero@gmail.com
}

\section{Carla Corradi-Perini}

Pontifícia Universidade Católica do Paraná

E-mail: carla.corradi@pucpr.br 
Resumo

Abstract

Key words

Bioética; humanização da assistência; políticas públicas de saúde; sistema único de saúde.

Bioethics; humanization of assistance; public health policies; unified health system.

0 objetivo era discutir a possibilidade de a ética dos cuidados servir como base para a implementação da Política Nacional de Humanização (PNH) nas instituições de saúde brasileiras. Partindo da análise documental e revisão integrativa, emergiram quatro categorias temáticas: humanização na relação profissional/paciente e os direitos dos utentes; humanização e a eficácia do modelo de atenção voltado para a integralidade; humanização nos processos de trabalho: uma práxis dialogal entre os profissionais de saúde; e humanização na formação e capacitação dos profissionais de saúde. Aética dos cuidados pode dar suporte à humanização na saúde, enquanto micropolítica, viabilizando a práxis dialogal entre os sujeitos.

The objective was to discuss the possibility of ethics of care as a basis for the implementation of the National Humanization Policy (PNH) in Brazilian health care institutions. Four thematic categories emerged from a documentary analysis and integrative review: humanization in the professional and patient relationship and the rights of users; humanization and the effectiveness of the attention model focused on integrality; humanization in work processes: a dialogical praxis among health professionals and; humanization in training and qualification of health professionals. The ethics of care can support the humanization in health, as micropolitics, allowing the dialogical praxis among the subjects.

Recibido: 24/12/2017. Aceptado: 02/04/2018 


\section{Introdução}

O Sistema Único de Saúde (SUS) brasileiro foi implementado na década de 1970, a partir da chamada Reforma Sanitária Brasileira, que instituiu a saúde como direito universal e igualitário (Brasil, 1988) visando diminuir as desigualdades sociais e restabelecer a democracia no país (Levcovitz, Lima, \& Machado, 2001; Dowbor, 2009). Para incluir todos os atores participantes do processo de produzir saúde, o SUS aposta na humanização enquanto política pública hábil a proporcionar mudanças na qualidade dos cuidados em saúde no país. Diante disso, em 2003 foi criada

A interdependência às relações
do cuidado é associada como
uma atitude essencialmente
humana
a Política Nacional de Humanização (PNH) brasileira que visa uma mudança de paradigma, ou seja, uma nova construção cultural das relações envolvidas no ato de cuidar de vidas humanas (Boff, 1999; Ayres, 2005; Zoboli, 2010; Brasil, 2010).

Entretanto, apesar da proposta da PNH de horizontalidade das relações para transformação da assistência em saúde no Brasil, o conceito de 'humanização' trazido pela $\mathrm{PNH}$ parece carecer de noções que levem à reflexão bioética e ética a serem incluídas nas práticas em saúde. E essa carência merece especial atenção à medida que o cuidado tem perdido sua posição central quanto à dimensão intersubjetiva diante das inovações no campo da saúde, da formação tecnicista, dos avanços tecnocientíficos e sua perspectiva econômica, e do excesso de protocolos inseridos nos espaços de assistência.

Nesse cenário, a ética do cuidado ganha destaque, ficando nítida a necessidade de reflexão acerca de como o ato relacional do cuidar do outro é observado nos ambientes de assistência à saúde. Para Zoboli $(2010$, p. 365) "a ética do cuidado valoriza o reconhecimento mútuo das relações interpessoais, ou seja, a interconexão e a interdependência humanas que resultam na intersubjetividade ética", permitindo que todos os envolvidos sejam corresponsáveis pela produção de saúde. A ética do cuidado trata de problemas éticos originados de responsabilidades conflitantes, visto o caráter relacional do cuidado.

A interdependência às relações do cuidado é associada por Boff (1999) como uma atitude essencialmente humana. Segundo o autor (1999, p. 33): "Cuidar é mais que um ato, é uma atitude [...]. Representa uma atitude de ocupação, preocupação, de responsabilização e de envolvimento afetivo com o outro". Cuidar é uma relação que se estabelece de forma solidária, proveniente de uma construção única, de um vínculo afetivo que abrange o caráter subjetivo existente em cada contexto vivenciado. Entende-se como uma atitude de atenção para com o outro e da consideração desse como sujeito digno de cuidados.

Nesse sentido, o cuidar é entendido por Torralba Roselló (2009) como uma arte que necessita harmonizar três pontos relevantes: a técnica, a intuição e a sensibilidade. 0 autor (Torralba Roselló, 2009) ainda enfatiza que o processo de cuidar deve se desenvolver pelo elemento linguístico, ou seja, pelo diálogo, pois é nele que se dá a interação e se concretiza o reconhecimento do outro. Para Cortina (2016) é necessário ir contra a razão instrumental e se fazer sobressair o compromisso do cuidado com o outro. Por- 
tanto, uma transformação da realidade só será possível a partir do encontro da técnica com a compaixão, a solidariedade e a empatia.

Enfim, a ética do cuidado está na essência do ser humano, ela é criada nas interdependências que se dão nas relações pessoais, profissionais e sociais, permitindo se estabelecer uma relação de troca com o melhor cuidado que possa oferecer, levando em consideração todos os aspectos que permeiam as intersubjetividades das relações humanas envolvidas.

Portanto, o presente trabalho teve como objetivo discutir a possibilidade da ética do cuidado servir como base para a implementação da PNH nas instituições brasileiras de assistência em saúde, viabilizando uma melhor compreensão das ações norteadoras propostas e sua aplicabilidade ao ser inserida como elemento teórico capaz de proporcionar a prática dialógica e a reflexão ética.

\section{Metodologia}

Realizou-se, primeiramente, a leitura e análise do documento "Política Nacional de Humanização: documento base para gestores e trabalhadores do SUS - Humanizasus", objetivando-se compreender as fragilidades existentes na proposta de humanização dessa política pública brasileira. Poste-

Uma transformação da

realidade só será possível

a partir do encontro da

técnica com a compaixão, a

solidariedade e a empatia riormente, utilizou-se o método revisão integrativa visando obter um levantamento dos autores que discutem o tema da humanização associado à ética do cuidado.

A partir da associação dos descritores: "ética do cuidado e humanização", acessados no portal de periódicos CAPES, somente artigos revisados por pares foram selecionados, sem definição de período de publicação. A busca resultou em um total de 14 artigos, no período de setembro de 2016. Foram excluídos os artigos que não estabeleceram aproximação com a proposta da pesquisa, com isso, 8 artigos foram considerados para a elaboração do presente artigo, que possibilitaram responder à questão norteadora "Quais as interfaces da ética do cuidado com a política nacional (brasileira) de humanização que podem auxiliar na implementação desta nos espaços de assistência à saúde?" Foi realizada leitura crítica por meio de exploração, interpretação, discussão e categorização dos artigos selecionados, e por fim a definição dos eixos temáticos.

\section{Resultados e Discussão}

Para os estudos analisados a partir da associação dos descritores "ética do cuidado e humanização", esta pesquisa resultou em: dificuldades encontradas no aspecto relacional entre profissional e paciente e a possibilidade de concretizar uma melhoria nessa relação via esclarecimento dos direitos dos usuários; necessidade de um mo- 
delo de atenção voltado para a efetividade dos princípios do SUS, sendo apontado o princípio da integralidade como foco para a efetividade das ações em saúde; eficácia dos processos de trabalho quando relacionados à qualidade das interações entre os profissionais que compõe o setor da saúde e; formação e capacitação como uma via fundamental para a humanização e as transformações na assistência em saúde. Portanto, as seguintes categorias foram criadas no intuito de aprofundar a discussão das temáticas a pouco apontadas: I - A humanização na relação profissional e paciente e os direitos dos usuários; II - A humanização e a efetividade do modelo de atenção voltado para a integralidade; III - A humanização e os processos de trabalho: uma práxis dialógica entre os profissionais da saúde; e IV - A humanização via formação e capacitação dos profissionais da saúde (Quadro 1).

\subsection{Humanização na relação profissional-paciente e os direitos dos usuários}

A prática dialógica se faz fundamental para compreender as intersubjetividades envolvidas nas relações de assistência em saúde, principalmente quando se fala em humanização do cuidado. De acordo com Araújo e Ferreira (2011) a relação entre profissional e paciente é fruto da associação entre a ética e a humanização, enquanto vínculo de diálogo e informação que são estabelecidos nos processos de cuidado. Aspectos esses que fazem interface com as ideias de Boff (1999) e Torralba-Roselló (2009).

\begin{tabular}{|c|c|c|c|c|}
\hline Categorias & Autor/ano & Metodologia & Periódico & Interfaces \\
\hline $\begin{array}{l}\text { I. Humanização na } \\
\text { relação profissional } \\
\text { e paciente e os } \\
\text { direitos dos usuários }\end{array}$ & $\begin{array}{l}\text { Araújo \& Ferreira, } 2010 \\
\text { Gomes \& Ramos, } 2015 \\
\text { Nations \& Gomes, } 2007 \\
\text { Zampieri \& Erdmann, } \\
2010\end{array}$ & $\begin{array}{l}\text { Entrevista } \\
\text { Entrevista } \\
\text { Entrevista } \\
\text { Entrevista }\end{array}$ & $\begin{array}{l}\text { Rev. bras. Enferm. } \\
\text { Interface comun. } \\
\text { saúde educ. } \\
\text { Cad. saúde pública. } \\
\text { Rev. bras. saúde } \\
\text { matern. infant. }\end{array}$ & $\begin{array}{l}\text { Relacionam a humanização } \\
\text { à qualidade dos vínculos } \\
\text { estabelecidos e a boa } \\
\text { comunicação entre } \\
\text { profissional e paciente } \\
\text { como fundamental para que } \\
\text { se possa exercer os direitos } \\
\text { dos usuários. Alguns } \\
\text { também trazem temas } \\
\text { referentes ao acolhimento, } \\
\text { protagonismo e autonomia }\end{array}$ \\
\hline $\begin{array}{l}\text { II. Humanização } \\
\text { e a efetividade do } \\
\text { modelo de atenção } \\
\text { voltado para a } \\
\text { integralidade }\end{array}$ & $\begin{array}{l}\text { Ayres, } 2009 \\
\text { Zampieri \& Erdmann, } \\
2010\end{array}$ & $\begin{array}{l}\text { Ensaio } \\
\text { Entrevista }\end{array}$ & $\begin{array}{l}\text { Saúde Soc. } \\
\text { Rev. bras. saúde } \\
\text { matern. infant. }\end{array}$ & $\begin{array}{l}\text { Relacionam a humanização } \\
\text { à integração da equipe } \\
\text { e articulação da rede de } \\
\text { serviços em saúde. A } \\
\text { eficácia da integralidade } \\
\text { enquanto operacionalização } \\
\text { e sinergismo da prática } \\
\text { em saúde e adaptada } \\
\text { aos projetos de felicidade } \\
\text { daquele que é assistido }\end{array}$ \\
\hline
\end{tabular}




\begin{tabular}{|c|c|c|c|c|}
\hline $\begin{array}{l}\text { III. Humanização } \\
\text { e os processos de } \\
\text { trabalho: uma práxis } \\
\text { dialógica entre os } \\
\text { profissionais da } \\
\text { saúde }\end{array}$ & $\begin{array}{l}\text { Costa, Figueiredo, \& } \\
\text { Schaurich, } 2009 \\
\text { Gomes \& Ramos, } \\
2015 \\
\text { Heckert, Passos, \& } \\
\text { Barros, } 2009 \\
\text { Junges et al., } 2011\end{array}$ & $\begin{array}{l}\text { Entrevista } \\
\text { Seminário }\end{array}$ & $\begin{array}{l}\text { Interface comun. } \\
\text { saúde educ. } \\
\text { Interface comun. } \\
\text { saúde educ. } \\
\text { Interface comun. } \\
\text { saúde educ. } \\
\text { Interface comun. } \\
\text { saúde educ. }\end{array}$ & $\begin{array}{l}\text { Relacionam a humanização } \\
\text { aos vínculos criados nos } \\
\text { processos de trabalho, a } \\
\text { prática dialógica como } \\
\text { meio de ampliar a qualidade } \\
\text { das interações entre os } \\
\text { profissionais que compõe a } \\
\text { equipe de saúde e estimular } \\
\text { o comprometimento } \\
\text { individual e coletivo. } \\
\text { Alguns trazem para o } \\
\text { debate a clínica ampliada, } \\
\text { a corresponsabilidade e a } \\
\text { cogestão }\end{array}$ \\
\hline $\begin{array}{l}\text { IV. Humanização } \\
\text { via formação e } \\
\text { capacitação dos } \\
\text { profissionais da } \\
\text { saúde }\end{array}$ & $\begin{array}{l}\text { Araújo \& Ferreira, } 2010 \\
\text { Costa, Figueiredo, \& } \\
\text { Schaurich, } 2009 \\
\text { Gomes \& Ramos, } 2015 \\
\text { Heckert, Passos, } \\
\text { Barros \& 2009 } \\
\text { Nations \& Gomes, } 2007 \\
\text { Zampieri \& Erdmann, } \\
2010\end{array}$ & $\begin{array}{l}\text { Entrevista } \\
\text { Entrevista } \\
\text { Entrevista } \\
\text { Seminário } \\
\text { Entrevista } \\
\text { Entrevista }\end{array}$ & $\begin{array}{l}\text { Rev. bras. Enferm. } \\
\text { Interface comun. } \\
\text { saúde educ. } \\
\text { Interface comun. } \\
\text { saúde educ. } \\
\text { Interface comun. } \\
\text { saúde educ. } \\
\text { Cad. saúde pública. } \\
\text { Rev. bras. saúde } \\
\text { matern. infant. }\end{array}$ & $\begin{array}{l}\text { Relacionam a humanização } \\
\text { à necessidade de } \\
\text { transformação dos } \\
\text { processos de formação em } \\
\text { saúde, sugerem a inserção } \\
\text { de currículos atentos } \\
\text { às demandas sociais e } \\
\text { voltados para os propósitos } \\
\text { do SUS. A composição } \\
\text { dos saberes para além } \\
\text { dos protocolos e técnicas, } \\
\text { mas que priorizem a ética } \\
\text { e a qualidade das relações } \\
\text { humanas que envolvem o } \\
\text { cuidado em saúde }\end{array}$ \\
\hline
\end{tabular}

Nesse sentido, uma das formas de garantir o direito à saúde do paciente é o acesso às informações sobre a condição em que ele se encontra e as alternativas de tratamentos possíveis, dessa forma permite-se a autonomia e protagonismo dos sujeitos perante sua própria saúde (Araújo \& Ferreira, 2011).

No entanto, Gomes e Ramos (2015) entendem que a humanização em saúde seria observada caso ocorresse uma transformação das relações envolvidas no processo de cuidar, enquanto sentimento de alteridade e comprometimento solidário. Defendem que uma dificuldade para a construção desse novo paradigma é o modelo mercadológico que se observa na saúde, no qual o individualismo e o foco na técnica se fazem predominantes no caráter dos profissionais da saúde.

Dessa forma, os autores (Gomes \& Ramos, 2015) pretendem uma mudança no modo de produzir saúde e como essa se dá no âmbito das relações, tendo como estratégia fundamental a competência comunicacional para construir mutuamente o conhecimento, com engajamento e responsabilidade social dos profissionais da área, como já discutido por Cortina (2016) e Zoboli (2010).

Nations e Gomes (2007) abordam a importância da comunicação que o profissional deve estabelecer com o paciente, e acrescentam a isso a necessidade de se utilizar 
uma linguagem apropriada e clara para cada sujeito. Afirmam (Nations \& Gomes, 2007, p. 2110) que: "O paciente recrimina a linguagem técnica, objetiva, proposital e centrada na doença, que somente transmite informação".

A qualidade do cuidado está

mais próxima ao âmbito das

competências humanas que

das habilidades técnicas

As autoras (Nations \& Gomes, 2007, p. 2109) ainda enfatizam que: "Indiscutivelmente a competência humana do profissional é mais valorizada do que seu know-how técnico. Não basta fazer uma ação mecanicamente correta, é necessário zelar a pessoa, executar com delicadeza, sem causar danos". Nesse sentido, a qualidade do cuidado está mais próxima ao âmbito das competências humanas do que das habilidades técnicas, se aproximando também com as ideias de Cortina (2016) e Zoboli (2010).

Zampieri e Erdmann (2010) trazem a necessidade do empoderamento dos usuários enquanto cidadãos dignos de direitos, do protagonismo nos processos de produzir saúde e o esclarecimento de quais são os direitos para poderem ser reivindicados. Assim, para que os usuários possam exercer seus direitos e protagonismo, é fundamental aproximar humanização e direitos humanos, como salientam (Zampieri \& Erdmann, 2010, p. 362-363):

\footnotetext{
O conceito de humanização no campo da saúde surge vinculado à questão dos direitos humanos, tendo como núcleo as ideias de dignidade e respeito à vida humana, e à ética na relação entre usuários e profissionais. A percepção e o conhecimento de ser titular de direitos é pressuposto essencial para que o ser humano possa compreender uma situação concreta como injusta, como violação ou negação de um direito e, consequentemente, exigir que tal direito seja cumprido.
}

Contudo, essa categoria visou discutir a humanização a partir dos vínculos criados na relação profissional e paciente, pois, no Brasil, os serviços de saúde são permeados pelo desrespeito e desatenção com seus usuários. Por esse motivo, os artigos supracitados apontam a necessidade de um modelo de saúde que seja menos centrado nas técnicas e instrumentos e mais no ser humano e nas suas intersubjetividades. Além disso, destacam a importância do profissional no sentido de fomentar o empoderamento dos usuários para garantia de direitos, do preparo comunicacional e do desenvolvimento de virtudes como alteridade, empatia e solidariedade para a prática dos profissionais da saúde.

\subsection{Humanização e a efetividade do modelo de atenção voltado para a integralidade}

Ayres (2009) enfatiza que entre os princípios que norteiam o Sistema Único de Saúde brasileiro (universalidade, equidade e integralidade) é fundamental dar foco à integralidade, visto que isso permitirá resolver os desafios da efetividade do acesso à saúde. 0 autor (Ayres, 2009) alega que a universalidade e a equidade correm o risco de ficar 
no plano ideológico, no entanto, a integralidade é o princípio mais palpável e concreto, uma vez que diz respeito às formas de operacionalizar o acesso à saúde.

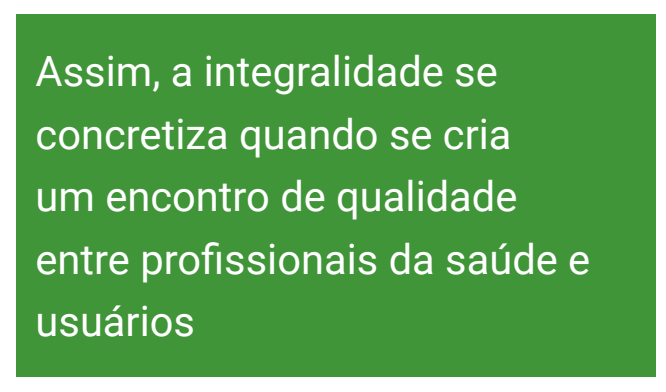

Ao salientar as relações dialógicas advinda dos encontros e as intersubjetividades no cotidiano, o autor (Ayres, 2009) se aproxima das ideias de Boff (1999) e Torralba-Roselló (2009), o cuidado é construído de forma sensível e em conformidade com a felicidade daquele que o recebe. Assim, a integralidade se concretiza quando se cria um encontro de qualidade entre profissionais da saúde e usuários, já que é no resultado positivo dessa relação que se dá o cuidado em si e, pautado na construção dos diferentes saberes, não dependendo apenas das técnicas e tecnologias que o profissional e a instituição possuem.

Os autores Zampieri e Erdmann (2010) evidenciam a importância do cuidado integral e ético, entretanto aspectos que visam apenas a técnica corroboram para que existam impedimentos na efetivação da integralidade, como apontados anteriormente por Cortina (2016) e Zoboli (2010), como a atuação isolada dos profissionais de saúde e voltada para a produtividade e agilidade no atendimento. Zampieri e Erdmann (2010) enfatizam ser algo advindo de uma formação reducionista e hospitalocêntrica, que desconsidera a multidimensionalidade de cada usuário e suas peculiaridades.

Sendo assim, como fundamental para se alcançar a atenção integral em saúde está a articulação da rede de serviços de saúde, além da integração da equipe e seus diferentes saberes envolvidos a fim de proporcionar um trabalho interdisciplinar, conforme corroborado pelas autoras supracitadas $(2010$, p. 363):

\footnotetext{
A integralidade, em nível micro, deve ser fruto do esforço e da confluência dos vários saberes de uma equipe multiprofissional para traduzir e atender as necessidades de saúde, sendo plena quando há articulação nos serviços de saúde, entre eles e com outras instituições sociais. A integralidade ampliada seria a relação articulada, complexa, complementar e dialética, entre a máxima integralidade no cuidado dado pelo profissional, pela equipe e rede de serviços de saúde.
}

Nesse sentido, os artigos inseridos nessa categoria salientaram a importância da integralidade e a necessidade de uma mudança no paradigma da atenção em saúde no Brasil, buscando uma transformação que gere cooperação entre os serviços prestados, maior mobilização e participação social e uma mudança na postura ética dos profissionais de saúde e gestores. Sendo que, só a partir disso, será possível uma reflexão das práticas em saúde e do atendimento integral e humanizado.

\subsection{Humanização e os processos de trabalho: uma práxis dialógica entre os profissionais de saúde}

Com relação à humanização proveniente dos vínculos criados no ambiente de trabalho em saúde, os estudos que se enquadram nessa temática relacionam a eficácia dos pro- 
cessos de trabalho com a qualidade das interações entre os profissionais que compõe a área da saúde, demonstrando a possibilidade de transformação por meio das práxis dialógica e consequente criação do vínculo de comprometimento.

Gomes e Ramos (2015) defendem que a dialogicidade é essencial nos ambientes de saúde, questão que condiz com o pensamento de Torralba-Roselló (2009). Explanam (Gomes \& Ramos, 2015) que há uma necessidade social do comprometimento individual, coletivo e da solidariedade dos profissionais da saúde para a melhoria da qualidade dos serviços prestados, identificando-se com as ideias de Cortina (2016) e Zoboli (2010).

Entretanto, para isso, é relevante uma transformação das práticas do SUS, para Gomes e Ramos (2015) a prestação de serviço tem sido embasada apenas no âmbito da relação contratual e uma mudança deve-se iniciar pela forma como os vínculos desses processos de trabalho são criados, uma vez que o comprometimento surge quando se permite a participação coletiva nas decisões. Ou seja, a melhoria da qualidade dos serviços em saúde no Brasil deve acontecer de forma participativa e cooperativa, mesmo sabendo da existência de barreiras para tal fim, como afirmam os autores (Gomes \& Ramos, 2015, p. 17):

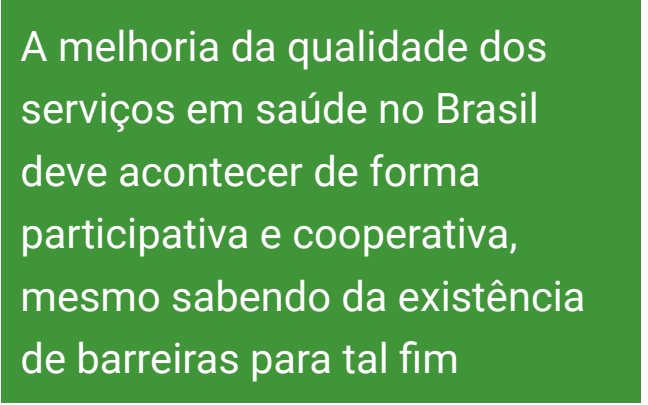

Mesmo com deficiências estruturais e organizativas, parece necessário mobilizar uma reflexão-ação coletiva em experiências de grupalidade, potencializada pelos sujeitos e pelos próprios gestores, que cultive novos sentidos e imaginários em equipes/coletivos, formais e não formais. Redes de cooperação e interação que ampliam o sentido do eu nos nós ou que sensibilizam para valores e benefícios coletivos, em relações horizontais, sem hierarquia e dependência, estimulam a capacidade criativa, solidária e dialógica dos sujeitos.

Heckert, Passos e Barros (2009), discutem os conceitos de humanização no contexto atual do financiamento da saúde pública do Brasil e da consequente precarização dos processos de trabalho em saúde. Utilizam-se da proposta da PNH para expressar como ela tem influenciado a valorização do profissional na rede do SUS, ao afirmarem (Heckert, Passos, \& Barros, 2009, p. 495) que: "[...] a PNH busca fomentar, nos atores que constroem os processos de trabalho - rede, o exercício de suas condições como protagonistas de análises compartilhadas e intervenções nos espaços de trabalho".

Nesse sentido, a PNH brasileira representa uma abertura para a efetiva participação dos trabalhadores nas formas de gerir e cuidar em saúde, fazendo-os parte integrante do todo e criadores da própria gestão, isso estimula o sentimento de comprometimento individual e coletivo. A prática dialógica permite a horizontalidade das relações e é considerada uma ferramenta essencial da humanização, ela se dá por meio da troca de ideias entre sujeitos de diferentes hierarquias (Heckert, Passos, \& Barros, 2009).

Junges et al. (2011) apresentam um estudo dos desafios observados em uma unidade de atenção primária à saúde no que se refere a efetivação da humanização segundo as diretrizes propostas pela PNH e a qualidade da relação interpessoal por meio do diálogo. Expõem (Junges et al., 2011) que os trabalhadores da unidade analisada, diante ao 
excesso de demanda e pouco espaço físico, executam suas funções de forma isolada e não formalizam reuniões e ocasiões para dialogar a respeito das situações vivenciadas na rotina de trabalho.

Visto esse panorama, da ausência de construção participativa dos meios de produzir saúde, existe a necessidade de transformação desses processos de trabalho, ao dar importância ao sentimento de pertencimento e de comprometimento que os profissionais devem estabelecer com o ambiente e atividade que exercem, apenas a boa intenção do profissional de forma individual não basta, mas cabe à gestão oportunizar

A moral nas práticas da

saúde não pode estar

fundada nas boas intenções

dos profissionais, mas na

responsabilidade em assumir

conjuntamente, como equipe

multiprofissional, a gestão da

unidade a união da equipe para as tomadas de decisões de maneira coletiva. Diante disso, Junges et al. (2011, p.761) afirmam:

A estratégia depende, essencialmente, de uma mudança nos processos de trabalho e de um respeito pelos direitos do próprio profissional. Ele precisa se sentir parte do processo, corresponsável na cogestão da unidade. Por isso a humanização não depende apenas da boa vontade do profissional, mas de seu comprometimento com o processo de trabalho regido pela PNH. Neste sentido, a moral nas práticas da saúde não pode estar fundada nas boas intenções dos profissionais, mas na responsabilidade em assumir conjuntamente, como equipe multiprofissional, a gestão da unidade.

Costa, Figueiredo e Schaurich (2009) apontam que além da empatia, responsabilidade e cuidado que o agente de saúde deve ter, deve-se observar a valorização dos trabalhadores da saúde e as transformações na forma de gerir e administrar as práticas de saúde, com o objetivo de qualificar os serviços prestados. Por esse motivo encontram-se os seguintes obstáculos para efetivação da humanização: profissionais pouco preparados e comprometidos para implementar a PNH brasileira e dificuldades nas relações interpessoais entre os membros da equipe de saúde.

Com o intuito de relacionar a qualidade dos processos de trabalhos com a humanização, os estudos aqui agregados resultaram na importância da valorização dos profissionais da saúde, bem como desses estarem envolvidos nos processos de cuidar e gerir distintos setores da saúde, por intermédio do diálogo e do comprometimento individual e coletivo como instrumentos fundamentais na modificação da qualidade desses serviços. Sendo aqui permeados por pensamentos fundamentados em Boff (1999), Torralba-Roselló (2009), Cortina (2016) e Zoboli (2010).

\subsection{Humanização via formação e capacitação dos profissionais da saúde}

Nessa categoria encontram-se os artigos que abordam a formação e a capacitação como via fundamental para transformações na assistência em saúde, capazes de propagar uma nova cultura de humanização em saúde. 
Nota-se uma lacuna ética na formação do profissional de saúde. Uma vez que são formados para atuarem em um modelo fragmentado, com foco na aplicação de técnica e do uso abusivo de tecnologia médica e exames, acabam por não se ajustarem ao atendimento da população usuária do SUS. Segundo Zampieri e Erdmann (2010, p. 363364) é necessário: "[...] a interdisciplinaridade e a formação humanizada e voltada para a lógica do Sistema Único de Saúde (SUS) [...]”. E apontam (Zampieri \& Erdmann, 2010, p. 364) como barreira para o cuidado integral: "[...] a formação dos profissionais e discentes, ainda dentro de uma lógica redu-

A formação acarreta na

qualidade com que o

profissional exerce seu trabalho,

seja no aspecto técnico ou

humano cionista e hospitalocêntrica, às vezes divergente da existente na assistência [...]".

Nesse sentido, a formação acarreta na qualidade com que o profissional exerce seu trabalho, seja no aspecto técnico ou humano. Para Araújo e Ferreira (2011, p.289): "[...] as ações técnicas-científicas são orientadas pela formação que conduzirá a atuação do profissional, seja no âmbito preciso da técnica, seja no âmbito das habilidades relacionais humanas [...]."

Sendo assim, conforme os fundamentos de Boff (1999), Torralba-Roselló (2009), Cortina (2016) e Zoboli (2010), é necessário fomentar um novo modelo de formação para a saúde com o intuito de orientar os profissionais a trabalharem com comprometimento e vínculo solidário com o outro, nas relações humanas que envolvem os cuidados em saúde.

Assim, como grande parte das instituições formadoras da área da saúde empregam metodologias descontextualizadas da realidade que será vivenciada na prática pelos profissionais, mudanças nos formatos dos currículos são fundamentais para a efetivação das propostas de humanização da assistência em saúde, principalmente no sistema de saúde brasileiro (Costa, Figueiredo, \& Schaurich, 2009).

Desse modo, é necessário ir além das regras e técnicas que são transmitidas no processo de formação, sendo necessário respeitar e ponderar cada situação visando a humanização dos serviços de saúde. Em vista disso, Nations e Gomes (2007, p. 2110) complementam:

\footnotetext{
Há ainda, a necessidade de incorporar, na formação, além dos conhecimentos técnico-instrumentais, outras formas de saber: significados e sentidos da realidade do paciente-cidadão, sua cultura, emoções e condições de vida. Edificar uma nova relação terapêutica, não de dominação, mas de respeito, afeto e vínculo, é um grande desafio, entre muitos, para uma conduta profissional solidária e uma gestão ética a fim de construir o hospital humano.
}

Portanto, a humanização deve ser agregada pelas instituições enquanto horizontalidade das relações e a partir da ética, como parte do currículo para uma formação do profissional da saúde que almeje construir vínculos solidários, que se concretizam tanto na atenção como na gestão dos serviços prestados (Heckert, Passos, \& Barros, 2009). 
Sabe-se que o Governo Brasileiro deve ser o grande incentivador dessas mudanças relacionais associadas às transformações efetivas no processo de formação do profissional da saúde, principalmente daqueles voltados para o serviço público. Nessa lógica, o Ministério da Educação (MEC) tem realizado alterações no sentido de humanizar o cuidado em saúde com a incorporação de novas competências na Lei de Diretrizes e Bases da Educação (LDB) e nas Diretrizes Curriculares Nacionais (DCN) do Brasil (Gomes \& Ramos, 2015).

Embora a formação tenha sido trazida aqui como instrumento fundamental para a alteração do paradigma no contexto da assistência em saúde, sabe-se que só será possível na harmonização dos diversos fatores que compõe a

Nos ambientes de assistência

em saúde as questões éticas

envolvidas na implementação

da política brasileira de

humanização incluem

diversidades de valores morais

e incertezas qualidade das práticas em saúde, como enfatizado por Zampieri e Erdmann (2010, p. 367):

[...] As alterações dependem da postura do profissional, da vontade dos gestores, da reestruturação na formação, da articulação de redes de cooperação entre serviços de saúde e setores sociais e da participação e mobilização social. Além disso, da escolha dos profissionais e da parceria na busca de pontos permeáveis no cotidiano do cuidar para além das divergências e convergências, transformando a realidade existente.

Contudo, nessa categoria se discutiu a importância da mudança dos currículos, principalmente no sentido de proporcionar vivências para que os sujeitos em processo de formação atribuam sentido próprio às relações sociais para que essa transformação aconteça. Além de uma formação e capacitação de recursos humanos em saúde que requer direcionamento para a realidade do sistema de saúde brasileiro, preocupando-se com o comprometimento dos profissionais em proporcionar um cuidado humanizado e com as necessidades sociais em saúde, essas ideias são fundamentadas por Boff (1999), Torralba-Roselló (2009), Cortina (2016) e Zoboli (2010).

\section{Considerações finais}

Pelo exposto, entende-se que a humanização associada aos temas da ética do cuidado deve ser incorporada práticas de assistência à saúde na forma de possibilitar o diálogo e a troca de ideias entre os sujeitos, considerando suas intersubjetividades. Visto que um dos objetivos da aproximação das propostas da PNH brasileira com a ética do cuidado é proporcionar a horizontalidade das relações entre os atores envolvidos.

Assim, os resultados dessa revisão integrativa indicaram que nos ambientes de assistência em saúde as questões éticas envolvidas na implementação da política brasileira de humanização incluem diversidades de valores morais e incertezas, e por sua complexidade a importância de reflexões e ações no âmbito de micropolíticas.

Por fim, faz-se necessária uma mudança de paradigma dos cuidados em saúde para enfrentar principalmente as realidades existentes no sistema de saúde brasileiro, que 
pode acontecer através da formação e capacitação dos profissionais voltada para uma cultura de humanização, o que inclui uma educação moral para o desenvolvimento das virtudes nas relações sociais.

\section{Bibliografia}

Ayres, J. R. C. M. (2005). Hermenêutica e humanização das práticas de saúde. Ciência \& Saúde Coletiva, 10(3), 549-560. DOI: https://doi.org/10.1590/S1413-81232005000300013

Ayres, J. R. C. M. (2009). Organização das ações de atenção à saúde: modelos e práticas. Saúde e Sociedade, 18(Suppl. 2), 11-23. DOI: https://doi.org/10.1590/S0104-12902009000600003

Araújo, F. P., \& Ferreira, M. A. (2011). Representações sociais sobre humanização do cuidado: implicações éticas e morais. Revista Brasileira de Enfermagem, 64(2), 287-293. DOI: https://doi.org/10.1590/S003471672011000200011

Boff, L. (1999). Saber cuidar. Ética do humano - compaixão pela terra. Petrópolis: Vozes.

Brasil. (1988). Constituição da República Federativa do Brasil. São Paulo: IMESP.

Brasil. (2010). Ministério da Saúde. Secretaria de Atenção à Saúde. Núcleo Técnico da Política Nacional de Humanização. HumanizaSUS: documento base para gestores e trabalhadores do SUS (4. ${ }^{a}$ edição). Brasília: Ministério da Saúde.

Cortina, A. (2016). Bioética para el siglo XXI: construyendo esperanza. Revista Iberoamericana de Bioética, (1), 1-12. DOI: https://doi.org/10.14422/rib.i01.y2016.001

Costa, S., Figueiredo, M. R. B., \& Schaurich, D. (2009). Humanização em Unidade de Terapia Intensiva Adulto (UTI): compreensões da equipe de enfermagem. Interface - Comunicação, Saúde, Educação, 13(Suppl. 2), 571- 580. DOI: https://doi.org/10.1590/S1414-32832009000500009

Dowbor, M. (2009). Da inflexão pré-constitucional ao SUS municipalizado. Lua Nova: Revista de Cultura e Política, (78), 158-222. DOI: https://doi.org/10.1590/S0102-64452009000300010

Gomes, D., \& Ramos, F. R. S. (2015). Solidariedade, aliança e comprometimento do profissional da saúde nas práticas do Sistema Único de Saúde (SUS): um debate bioético. Interface - Comunicação, Saúde, Educação, 19(52), 9-20. DOI: https://doi.org/10.1590/1807-57622014.0412

Heckert, A. L. C., Passos, E., \& Barros, M. E. B. (2009). Um seminário dispositivo: a humanização do Sistema Único de Saúde (SUS) em debate. Interface - Comunicação, Saúde, Educação, 13(Suppl. 1), 493-502. DOI: https://doi.org/10.1590/S1414-32832009000500002

Junges, J. R., Schaefer, R., Prudente, J., Mello, R. E. F., Silocchi, C., Souza, M., \& Wingert, G. (2011). A visão de moral dos profissionais de uma unidade básica de saúde e a humanização. Interface - Comunicação, Saúde, Educação, 15(38), 755-764. DOI: https://doi.org/10.1590/S1414-32832011000300011

Levcovitz, E., Lima, L. D., \& Machado, C. V. (2001). Política de saúde nos anos 90: relações intergovernamentais e o papel das Normas Operacionais Básicas. Ciênc. saúde coletiva, 6(2), 269-293. DOI: https://doi. org/10.1590/S1413-81232001000200002

Nations, M. K., \& Gomes, A. M. A. (2007). Cuidado, "cavalo batizado" e crítica da conduta profissional pelo paciente-cidadão hospitalizado no Nordeste brasileiro. Cadernos de Saúde Pública, 23(9), 2103-2112. DOI: https://doi.org/10.1590/S0102-311X2007000900018 
Torralba-Roselló, F. (2009). Antropologia do Cuidar. Petrópolis, Rio de Janeiro: Vozes.

Zampieri, M. F. M., \& Erdmann, A. L. (2010). Cuidado humanizado no pré-natal: um olhar para além das divergências e convergências. Revista Brasileira de Saúde Materno Infantil, 10(3), 359-367. DOI: https://doi. org/10.1590/S1519-38292010000300009

Zoboli, E. L. C. P. (2010). Intersubjetividade e cuidado. In L. Pessini, J. E. Siqueira \& W. S. Hossne (Org.), Bioética em tempos de incertezas (pp. 357-374). São Paulo: Loyola. 